\title{
Thermal Decomposition of Nitrated Tri-n-Butyl Phosphate in a Flow Reactor
}

\author{
Lalit K. Patil, ${ }^{1}$ Vilas G. Gaikar, ${ }^{1}$ Shekhar Kumar, ${ }^{2}$ U. Kamachi Mudali, ${ }^{2}$ and R. Natarajan ${ }^{2}$ \\ ${ }^{1}$ Department of Chemical Engineering, Institute of Chemical Technology, Mumbai 400019, India \\ ${ }^{2}$ Reprocessing Group, Indira Gandhi Centre for Atomic Research, Kalpakkam 603102, India
}

Correspondence should be addressed to Shekhar Kumar, shekhar@igcar.gov.in

Received 14 October 2012; Accepted 16 November 2012

Academic Editors: J. Canosa and S. Yin

Copyright (C) 2012 Lalit K. Patil et al. This is an open access article distributed under the Creative Commons Attribution License, which permits unrestricted use, distribution, and reproduction in any medium, provided the original work is properly cited.

\begin{abstract}
Tri-n-butyl phosphate (TBP) is a universal nuclear extractant, commercially used in the PUREX process for the last 60 years. However, it is prone to nitration and thermal degradation, and as a consequence a red-oil event may be initiated under several operating conditions resulting in severe pressurization of vessel/cell if venting is inadequate. In this work, an attempt was made to understand the reaction pathway of thermal decomposition of nitrated TBP in a flow reactor at atmospheric pressure. Many reaction products were identified and quantified by instrumental methods like HPLC-RI and GC-TCD. The experimental data was analysed with a power law model and the apparent rate constants were estimated. The activation energy for thermal decomposition of nitrated TBP, assuming an Arrhenius type of temperature dependency, was estimated to be $47.39 \pm 0.25 \mathrm{~kJ} \cdot \mathrm{mol}^{-1}$. The effect of both varying temperature and concentration of nitric acid on conversion of TBP into degradation products and products distribution was experimentally studied. Based on the experimental observations, a reaction mechanism framework for thermal decomposition of nitrated TBP is proposed.
\end{abstract}

\section{Introduction}

In nuclear fuel reprocessing industry, solvent extraction is a cost-effective process for separation of unused uranium and bred plutonium from the complex fuel matrix [1]. There are many solvents which can effectively extract uranium, plutonium, or thorium from nitric acid solutions but tri$n$-butyl phosphate (TBP) is one of the important organic solvents utilized during the acid extraction step in separation process at reprocessing facilities $[2,3]$. This is because of its overall superiority in operation, safety, physical properties, radiation resistance, and economics. One of the most desirable attributes of TBP is its high flash point, $146^{\circ} \mathrm{C}$, compared with other solvents. The reported boiling point and the density of TBP at $25^{\circ} \mathrm{C}$ is $289^{\circ} \mathrm{C}$ and $0.973 \mathrm{~g} / \mathrm{mL}$, respectively [4-6]. Most solvent extraction operations are conducted at ambient conditions without heating TBP and have been performed safely for decades. After the extraction process, raffinate containing fission products and dissolved TBP remains as highly active rad-waste which needs to be concentrated in the evaporator for storage and further management. During the evaporation process, water is evaporated continuously which results in separation of dissolved TBP from aqueous layer. At $130^{\circ} \mathrm{C}$, "red oil" (complexes of TBP and $\mathrm{HNO}_{3}$ ) is formed which further undergoes exothermic reactions. With continual concentration of aqueous phase, the rate of generation of gases overcomes the rate of its remove which increases the pressure of the evaporator and reaction goes in runaway condition resulting to explosion $[7,8]$. So far the history has registered several explosions occurring due to the decomposition of red oil [9-13].

The controls for temperature, pressure, mass, and concentration are the important factor for mitigation of red oil explosion. Maintaining the temperature below $130^{\circ} \mathrm{C}$ is generally accepted as a safe limit to prevent red oil explosion. Sufficient venting serves to keep pressure in control from destroying the process vessel, while, also, providing the means for evaporative cooling to keep red oil from reaching the runaway temperature. Mass control involves washing with a diluent or kerosene followed by enhanced settling in decanters to remove organics from the feed stream which are capable of producing red oil. Limiting the total available 


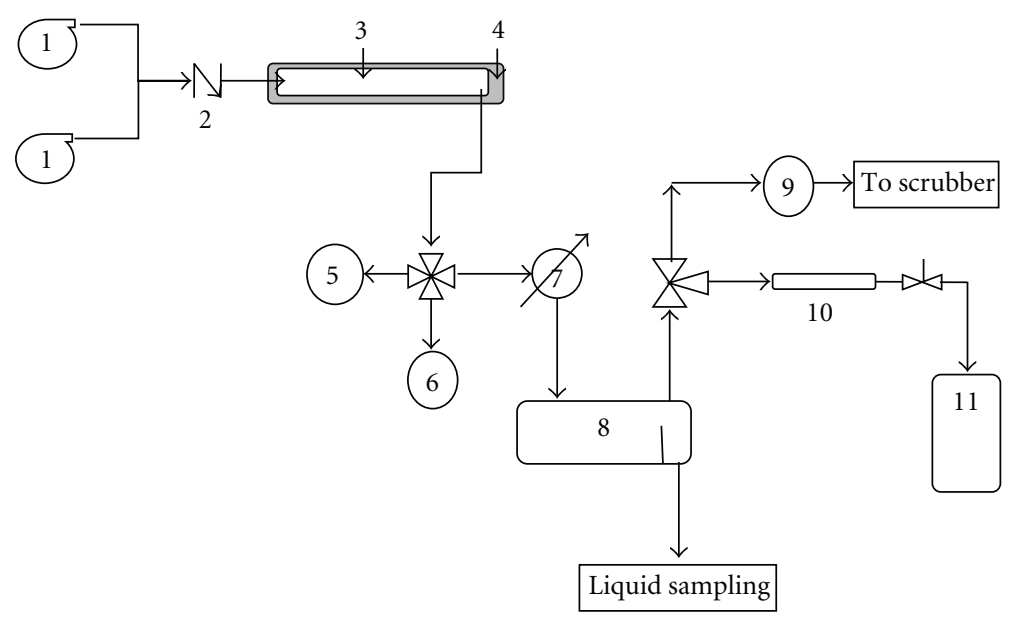

FIGURE 1: Schematic view of experimental setup for runaway reaction. (1) peristaltic pump, (2) non-return valve, (3) coiled reactor, (4) ceramic heater, (5) temperature controller, (6) pressure gauge, (7) condenser, (8) gas-Liquid separator, (9) digital flow meter, (10) gas sampling tube, (11) gas bladder.

TBP is an alternate mass control technique that mitigates the consequence of a red oil explosion by controlling its maximum available explosive energy. Finally, concentration control involves keeping the concentration of nitric acid below the $10 \mathrm{~mol} \cdot \mathrm{dm}^{-3}$. Controlling parameters should be used alone; rather, they should be used together to provide effective defence in depth for the prevention of a red oil explosion [14].

In order to effectively use the above mention control parameters, separation of TBP from aqueous raffinate and quantifying it up to sub-ppm level plays an important role from environmental safety perspectives [15]. In the PUREX process, where TBP exposed to acidic conditions (nitric acidaqueous phase) and gamma radiation ( $\mathrm{U}, \mathrm{Th}$, and fission products), undergoes hydrolytic and radiolytic reactions resulting into formation of some undesired components mainly dibutyl phosphate (DBP) and to a lesser extent monobutyl phosphate (MBP). Numerous analytical methods like GC-FID [16-19], titrimetry [20], complex-gravimetry [21], ion pair chromatography [22-24], colorimetry [25, 26], IR, UV-VIS, NMR spectroscopy [7, 22], and AAS [27] exist to determine TBP at higher concentration level. High speed isotachophoresis [28] was successfully used to analyze degradation mixture of TBP.

In this report, equilibrations of pure TBP and aqueous nitric acid solutions have been studied and solubility of TBP in different concentrations of nitric acid solution was determined. The equilibrated TBP further undergoes decomposition in continuous plug flow reactor. The continuous flow reactor was specially selected for the studies, from the safety point of view. The effect of concentration and temperature on the decomposition of equilibrated TBP has been studied. A detailed reaction mechanism for thermal decomposition of TBP-nitric acid was proposed on the basis of reaction products profile [29-35]. The data generated in these experiments can be useful to analyse pitfalls of vitrification process of radioactive waste after extraction process, namely, UREX, PUREX.

\section{Materials and Methods}

2.1. Material. Nitric acid (69\%-72\%), TBP (99\% purity), butanol (99.6\%, purity), phosphoric acid ( $>97 \%$ purity), and acetonitrile (HPLC grade) were procured from SD FineChem limited, Mumbai, India. A standard Mixture of MBPDBP $(46 \%-54 \%)$ was obtained from Indira Gandhi Centre for Atomic Research, Kalpakkam. Standard gases like $\mathrm{O}_{2}$, $\mathrm{CO}, \mathrm{H}_{2}, \mathrm{CO}_{2}$ and $\mathrm{C}_{1}-\mathrm{C}_{4}$ hydrocarbons were purchased from Alchemie gases, and other gases like $\mathrm{NO}, \mathrm{NO}_{2}$, and $\mathrm{N}_{2} \mathrm{O}$ were purchased from Amol gases and chemicals Pvt., Ltd., Mumbai, India.

2.2. Experimental Set Up for Runaway Reaction. The runaway reaction between TBP and $\mathrm{HNO}_{3}$ was conducted in a continuous flow tubular reactor SS $316(125 \mathrm{~cm}$ in length and $4 \mathrm{~mm}$ ID volumes). The reactor was placed in a ceramic furnace which can be electrically heated up to $575^{\circ} \mathrm{C}$. The temperature of the furnace was controlled by a temperature controller with K-type thermocouple. A peristaltic pump was used to charge TBP equilibrated with nitric acid into the reactor. Temperature indicator and pressure indicator were placed at the end of reactor using a four-way valve. The reactor was equipped with a metal condenser along with a water cooled jacket and a phase separator. The gaseous products were passed through to a digital gas flow meter for flow measurements of evolved gases. A schematic view of the experimental setup is shown in Figure 1.

2.3. Method of Analysis. The concentration of nitric acid in organic phase was measured by titration with aqueous $1.011 \mathrm{~mol} \cdot \mathrm{dm}^{-3} \mathrm{NaOH}$ solution. The amount of water in the organic phase was estimated by Karl-Fischer titration. The liquid products were analysed using a high performance liquid chromatography (HPLC) with refractive index detector using $5 \mu \mathrm{m}$ Hypersil $\mathrm{C} 18$ column of length $250 \mathrm{~mm}$. The column was mounted on a JASCO PU-980 HPLC chromatograph equipped with a 20 microlitre loop injector and a 


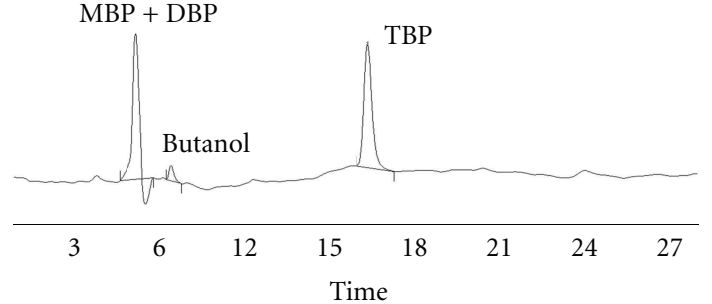

FIGURE 2: HPLC chromatogram showing liquid products, formed during thermal decomposition of equilibrated TBP, HPLC-RI method.

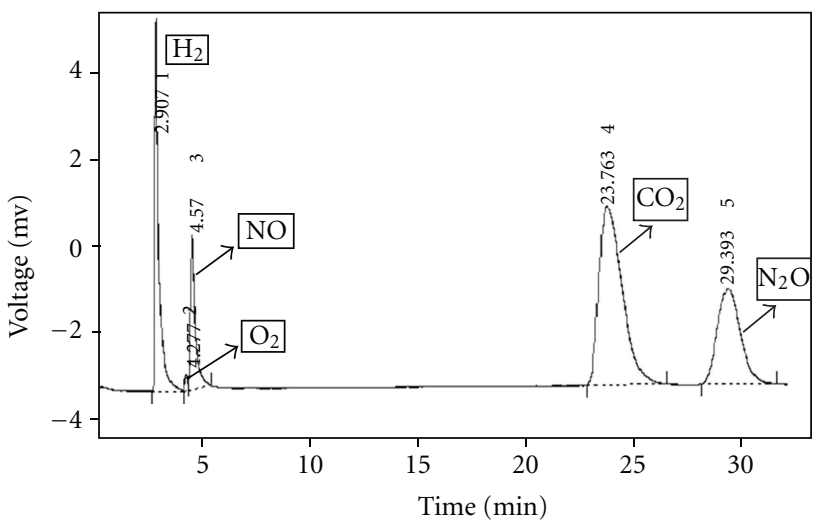

FIGURE 3: Gas chromatogram showing gaseous products of runaway reaction of TBP and nitric acid by GC-TCD method.

refractive index detector (Jasco RI-2031 plus). The column was equilibrated with $70 \%$ of acetonitrile and $30 \%$ de-ionized water as a mobile phase at a flow rate of $0.5 \mathrm{~mL} / \mathrm{min}$.HPLC chromatograph showing all the liquid products is labelled in Figure 2.

The qualitative and quantitative analysis of gaseous products was performed on a Chemito GC 8610 gas chromatograph equipped with a thermal conductivity detector (TCD). Gases evolved were separated on a Haysep D stainless steel packed column (25 feet in length, ID $2.4 \mathrm{~mm}$ ). The oven temperature and TCD's temperature were maintained constant at $35^{\circ} \mathrm{C}$ and $100^{\circ} \mathrm{C}$, respectively. Injector port's temperature was maintained at $35^{\circ} \mathrm{C}$. In GC-TCD method, nitrogen was used as a carrier gas to detect $\mathrm{H}_{2}, \mathrm{O}_{2}, \mathrm{CO}_{2}, \mathrm{NO}$, and $\mathrm{N}_{2} \mathrm{O}$, whereas hydrogen was used as a carrier gas to analyse $\mathrm{N}_{2}$. Flow rate of both carrier gases was maintained at $15 \mathrm{~mL} / \mathrm{min}$. GC chromatograph showing all the gaseous product is labelled in Figure 3.

2.4. Equilibrations of TBP with Different Concentration of Nitric Acid. The nitric acid solutions of 2, 4, 6, 8, 10, 12, and $14 \mathrm{~mol} / \mathrm{L}$ concentrations were prepared from $15.6 \mathrm{~mol} / \mathrm{L}$ stock solution of concentrated AR grade nitric acid and demineralized water of $18.2 \mathrm{M} \Omega \mathrm{cm}$ resistivity. These solutions were analyzed by titrating against a standard solution of $1.011 \mathrm{~mol} / \mathrm{L} \mathrm{NaOH}$ solution. Equilibration of TBP was performed by mixing one volume of $100 \%$ TBP and five volumes of nitric acid of different concentrations in a shaker for 24
TABLE 1: Acid uptake by TBP: analytical results.

\begin{tabular}{|c|c|c|c|}
\hline $\begin{array}{l}\text { Initial conc. of } \\
\text { nitric acid in } \\
\text { aqueous phase } \\
(\mathrm{mol} / \mathrm{L})\end{array}$ & $\begin{array}{l}\text { Conc. of nitric } \\
\text { acid in } \\
\text { equilibrated } \\
\text { aqueous phase } \\
\text { (mol/L) }\end{array}$ & $\begin{array}{l}\text { Conc. of nitric } \\
\text { acid in } \\
\text { equilibrated TBP } \\
\text { phase }(\mathrm{mol} / \mathrm{L})\end{array}$ & $\begin{array}{l}\text { Distribution } \\
\text { ratio }\end{array}$ \\
\hline 2 & 1.76 & 1.19 & 0.67 \\
\hline 4 & 3.53 & 2.18 & 0.61 \\
\hline 6 & 5.35 & 2.85 & 0.53 \\
\hline 8 & 7.45 & 3.14 & 0.42 \\
\hline 10 & 9.31 & 3.63 & 0.39 \\
\hline 12 & 11.46 & 4.12 & 0.36 \\
\hline 14 & 13.40 & 4.80 & 0.35 \\
\hline 15.6 & 15.10 & 5.49 & 0.35 \\
\hline
\end{tabular}

hours. After equilibration, aqueous and organic phases were separated in a glass separating funnel. Acidity of both phases was analyzed using acid-base titration with $1.011 \mathrm{~mol} / \mathrm{L}$ $\mathrm{NaOH}$ solutions.

2.5. Decomposition of Nitrated TBP in Continuous Tubular Reactor. Complete evacuation of reactor was implemented to study the effect of concentration. The temperature of outer wall of reactor was set to $158^{\circ} \mathrm{C}$ by heater which results in an inside temperature of reactor at $150^{\circ} \mathrm{C}$ under flow condition; for temperature studies it was varied from 140 to $180^{\circ} \mathrm{C}$, accordingly. Nitrated TBP was pumped through the reactor using peristaltic pump through nonreturn valves by means of silicon tubing at a flow rate of $0.5 \mathrm{~mL} / \mathrm{min}$. The reaction products were passed through chilled condenser and finally separated into liquid and gaseous phases. The gases were passed from the digital gas flow meter to measure the total volume of the gas produced. The gaseous products and liquid phase were collected and analyzed by gas chromatography and high pressure liquid chromatography respectively. These results are listed in Tables 4 and 5.

\section{Results and Discussion}

3.1. Equilibrium Studies. From the equilibration studies, it is clear that as concentration of nitric acid in aqueous phase increases, the ability of TBP to extract the nitric acid decreases. Acid uptake of the organic phase is listed in Table 1 . In case of the $2 \mathrm{~mol} / \mathrm{L}$ nitric acid, $60 \%$ nitric acid is extracted into organic phase whereas for concentrated nitric acid $(15.6 \mathrm{~mol} / \mathrm{L}), 35 \%$ of nitric acid is extracted into organic phase. The distribution ratio of nitric acid in water and TBP decreases as concentration of nitric acid increases but it was found to be constant at concentration of nitric acid $\geq 10 \mathrm{~mol} / \mathrm{L}$. Hence at higher concentration of nitric acid $(\geq 10 \mathrm{~mol} / \mathrm{L})$, the distribution ratio of nitric acid in water and TBP is 0.36 . As the concentration of nitric acid in aqueous phase increases, the solubility of TBP decreases and it was found that at higher concentration of nitric acid $(\geq 10 \mathrm{~mol} / \mathrm{L}$ ) TBP has no solubility in aqueous phase. The 
TABLE 2: Aqueous solubility of organic phase during experiment.

\begin{tabular}{lc}
\hline $\begin{array}{l}\text { Aqueous nitric acid conc. } \\
(\mathrm{mol} / \mathrm{L})\end{array}$ & $\begin{array}{c}\text { TBP content of aqueous phase } \\
(\mathrm{ppm})\end{array}$ \\
\hline 2 & 326 \\
4 & 276 \\
6 & 182 \\
8 & 94 \\
\hline
\end{tabular}

TABLE 3: Composition of gaseous products, formed during thermal decomposition of equilibrated TBP at $150^{\circ} \mathrm{C}$.

\begin{tabular}{lcccccc}
\hline $\begin{array}{l}\text { Equilibrated nitric } \\
\text { acid conc. in organic } \\
\text { phase (mol/L) }\end{array}$ & $\mathrm{N}_{2}$ & $\mathrm{H}_{2}$ & $\mathrm{O}_{2}$ & $\mathrm{NO}$ & $\mathrm{CO}_{2}$ & $\mathrm{~N}_{2} \mathrm{O}$ \\
\hline 1.19 & 7.0 & 8.99 & 9.41 & 2.75 & 38.20 & 33.66 \\
2.18 & 8.9 & 7.84 & 2.79 & 2.56 & 38.05 & 39.86 \\
2.85 & 9.8 & 6.48 & 2.73 & 4.72 & 39.60 & 36.65 \\
3.14 & 10.4 & 6.80 & 1.23 & 3.18 & 34.66 & 43.70 \\
3.63 & 12.1 & 8.06 & 1.72 & 3.28 & 34.33 & 40.47 \\
4.12 & 12.8 & 9.16 & 2.21 & 3.70 & 32.51 & 39.64 \\
\hline
\end{tabular}

aqueous solubility of TBP was estimated by HPLC method and the results are listed in Table 2.

3.2. Product Composition. Decomposition of nitrated TBP was carried out in a continuous plug flow reactor. The reaction mass was passed through ice cooled condenser so that condensable vapors can be condensed and further separated by phase separator. Liquid products were analyzed by HPLCRI method which shows the presence of MBP, DBP, butanol, and unreacted TBP. It was expected that nitric acid will lead to complete hydrolysis of TBP, but HPLC-RI method confirmed the absence of phosphoric acid. Gaseous products were transferred to digital gas flow meter which measured the total amount of gas generated during the reaction and collected in gas sampling tube with gas bladder and analyzed by GC-TCD method. The results showed that the presence of $\mathrm{H}_{2}, \mathrm{O}_{2}, \mathrm{~N}_{2}, \mathrm{CO}_{2}, \mathrm{NO}$, and $\mathrm{N}_{2} \mathrm{O}$. Although the gas produced initially was orange brown, which suggests the presence of $\mathrm{NO}_{2}$, GC-TCD method confirmed the absence of $\mathrm{NO}_{2}$ in the gaseous products. All the products were identified by comparing their retention indices with those of standard components.

3.3. Effect of Operating Variables on Thermal Decomposition of Nitrated TBP. The effect of operating variables on the single-phase thermal decomposition of nitrated TBP was studied by varying the temperature from $140^{\circ} \mathrm{C}$ to $180^{\circ} \mathrm{C}$ along with the concentration of nitric acid. For this study, three solutions of nitric acid in TBP with the respective concentrations of $2.85,3.14$, and $4.12 \mathrm{~mol} / \mathrm{L}$ were prepared by mixing respective aqueous nitric acid solutions of 6,8 and $12 \mathrm{~mol} / \mathrm{L}$ concentration with pure TBP for 24 hours. Effect of temperatures on gas generation during thermal decomposition of TBP equilibrated with 6,8 , and $12 \mathrm{~mol} / \mathrm{L}$ of nitric acid is depicted in Figure 4. It was also observed the
TABLE 4: Composition of liquid products, formed during thermal decomposition of equilibrated TBP at $150^{\circ} \mathrm{C}$.

\begin{tabular}{lccccc}
\hline \multirow{2}{*}{$\begin{array}{l}\text { Equilibrated nitric } \\
\text { acid conc. (mol/L) }\end{array}$} & TBP & MBP + DBP & Butanol & $\begin{array}{c}\text { Nitric } \\
\text { acid }\end{array}$ & Water \\
\hline 1.19 & 70.87 & 21.79 & 2.99 & 3.06 & 1.29 \\
2.18 & 62.23 & 25.47 & 3.46 & 6.91 & 1.93 \\
2.85 & 52.04 & 30.21 & 5.10 & 10.58 & 2.07 \\
3.14 & 48.88 & 33.50 & 3.99 & 11.42 & 2.21 \\
3.63 & 39.84 & 38.31 & 7.07 & 12.36 & 2.41 \\
4.12 & 34.70 & 41.91 & 7.34 & 13.12 & 2.93 \\
\hline
\end{tabular}

TABLE 5: Estimation of rate constant for thermal decomposition of nitrated TBP in a flow reactor.

\begin{tabular}{lcccc}
\hline $\begin{array}{l}\text { Temperature } \\
(\mathrm{K})\end{array}$ & $\begin{array}{c}\text { Initial } \\
(\mathrm{TBP}) \\
(\mathrm{moles})\end{array}$ & $\begin{array}{c}\text { Initial } \\
\left(\mathrm{HNO}_{3}\right) \\
(\mathrm{moles})\end{array}$ & $\begin{array}{c}\text { Final (TBP) } \\
(\text { moles })\end{array}$ & $\begin{array}{c}\text { Estimated } \\
\text { rate } \\
\text { constant } k\end{array}$ \\
\hline 413 & 0.031 & 0.031 & 0.014 & 0.012 \\
423 & 0.031 & 0.031 & 0.013 & 0.013 \\
433 & 0.031 & 0.031 & 0.0091 & 0.024 \\
443 & 0.031 & 0.031 & 0.0068 & 0.036 \\
453 & 0.031 & 0.031 & 0.0054 & 0.048 \\
\hline
\end{tabular}

increase of concentration of nitric acid enhanced gas yield as well as the rate of hydrolysis of TBP. Effect of temperatures on composition of gaseous products formed during thermal decomposition of TBP, equilibrated with 6,8 , and $12 \mathrm{~mol} / \mathrm{L}$ of nitric acid, is shown in Table 3 and Figures 5, 7, and 9, respectively. It suggests that large amount of nitrous oxide $\left(\mathrm{N}_{2} \mathrm{O}\right)$ was formed but concentration of nitrous oxide was found to decrease as the temperature was increased. With the increase in temperature, the decomposition of nitric acid increases which results in the increase in formation of nitrogen. The yield of hydrogen increased drastically at elevated temperatures $\left(160\right.$ to $\left.180^{\circ} \mathrm{C}\right)$. Small amount of nitric oxide and oxygen were observed in all cases. At higher temperature, yield of carbon dioxide was found to decrease as negligible amount of coke formation was observed at elevated temperature. Effect of temperatures on liquid product profile during thermal decomposition of TBP equilibrated with 6,8 , and $12 \mathrm{~mole} / \mathrm{L}$ of nitric acid is schematically shown in Table 4 and Figures 6, 8, and 10, respectively. It was also observed that conversion of TBP to degradation products increased with increase in prevailing acidity as well as temperature. As the TBP decomposition increased, the formation of MBP, DBP, and butanol also increased but the amount of butanol was not so significant. Vapor phase decomposition of butanol under oxidizing conditions yielded carbon dioxide and hydrogen. It is confirmed that concentration of nitric acid plays an important role during nitration/decomposition reactions of TBP. Thus, it is necessary to study the effect of nitric acid concentration on decomposition of nitrated TBP. For this purpose, TBP is equilibrated with 2, 4, 6 , 8,10 , and $12 \mathrm{~mol} / \mathrm{L}$ nitric acid. The reactor temperature is maintained at $150^{\circ} \mathrm{C}$. Figure 11 shows increasing yield of 


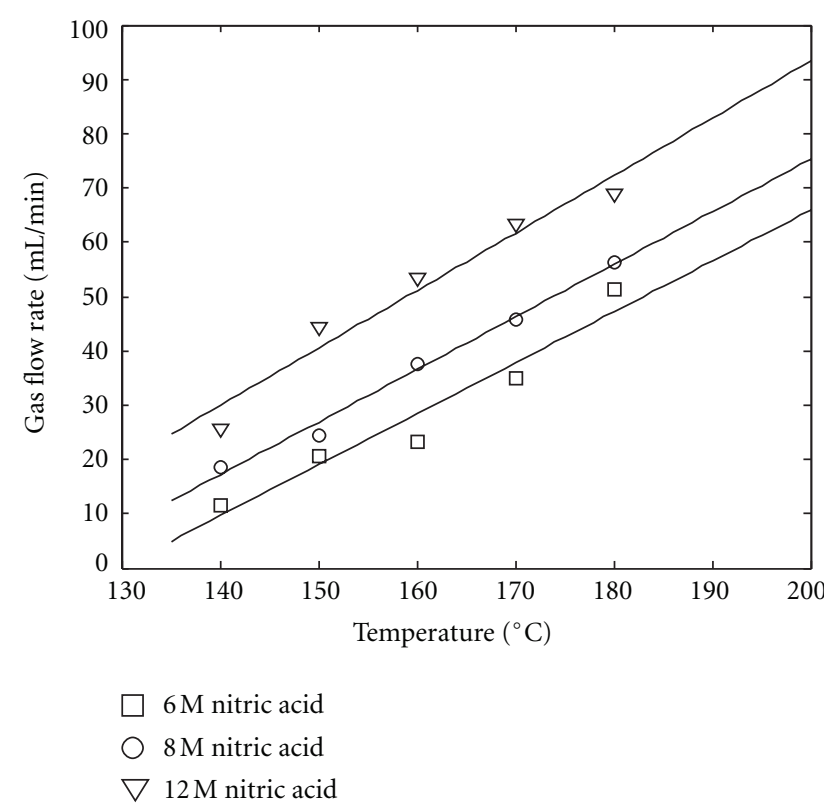

FIGURE 4: Effect of temperature on gases generation during the single phase decomposition of TBP equilibrated with different concentration of nitric acid.

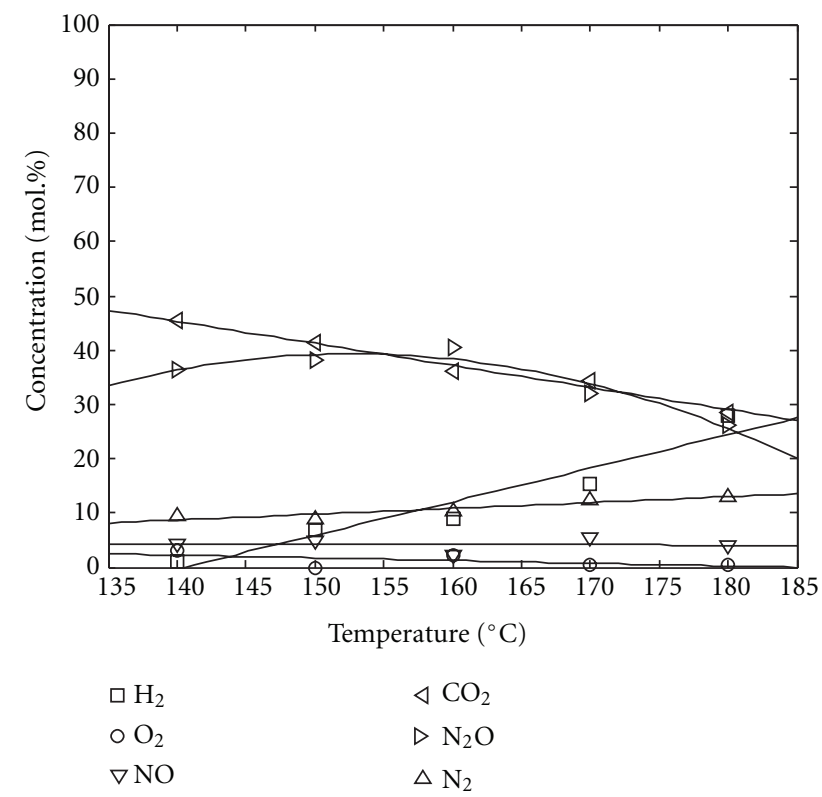

FIGURE 5: Effect of temperature on gas composition during the single-phase decomposition of TBP equilibrated with $6 \mathrm{~mol} / \mathrm{L}$ nitric acid.

gaseous product with the concentration of nitric acid in TBP. This may be partially attributed to production of butanol and butyl nitrate as decomposition products, as butyl nitrate is highly reactive at room temperature. The effect of nitric acid concentration on yield of gaseous and liquid products is shown in Figures 12 and 13, respectively.

3.4. Kinetics of Decomposition of TBP, Equilibrated with Nitric Acid. Single-phase decomposition of TBP equilibrated with

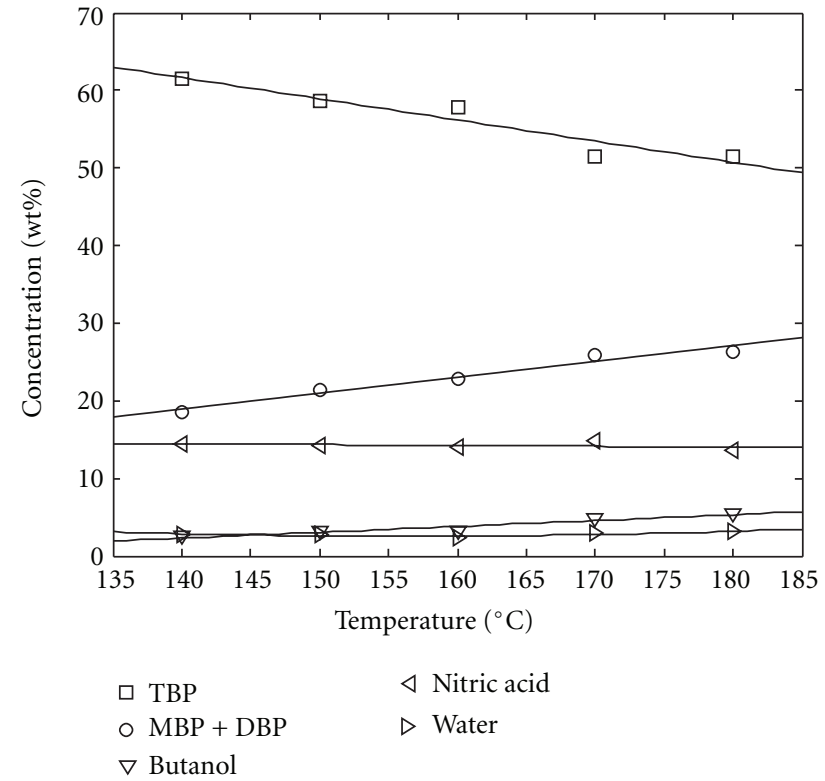

FIGURE 6: Effect of temperature on liquid product in weight percentage during the single-phase decomposition of TBP equilibrated with $6 \mathrm{~mol} / \mathrm{L}$ nitric acid.

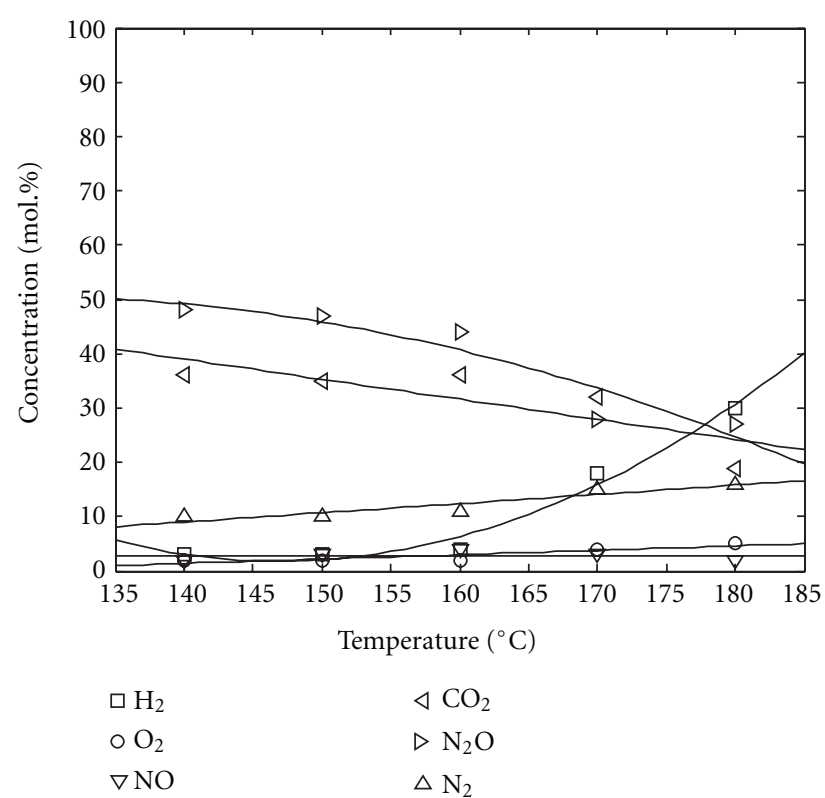

FIGURE 7: Effect of temperature on gaseous products in mole percentage during the single-phase decomposition of TBP equilibrated with $8 \mathrm{~mol} / \mathrm{L}$ nitric acid.

6,8 , and $12 \mathrm{~mol} / \mathrm{L}$ nitric acid was studied at temperatures ranging from $140^{\circ} \mathrm{C}$ to $180^{\circ} \mathrm{C}$ at atmospheric pressure. The reaction was found to follow first order with respect to TBP as well as nitric acid and overall second order. The rate equation could be written as follows:

$$
-r_{\mathrm{TBP}}=k \cdot C_{\mathrm{TBP}} \cdot C_{\mathrm{HNO}_{3}}
$$




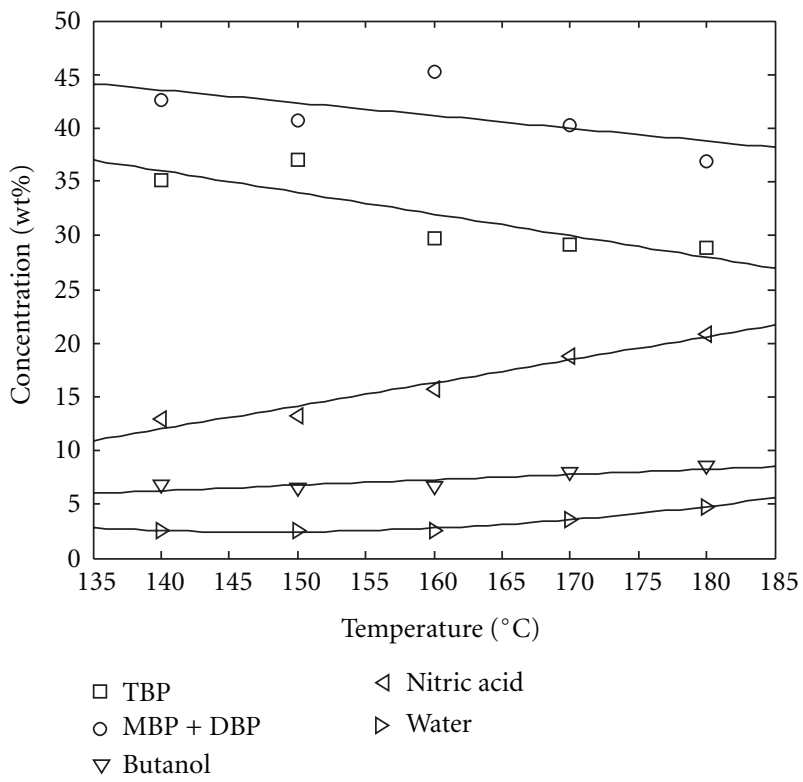

FIGURE 8: Effect of temperature on liquid product in weight percentage during the single-phase decomposition of TBP equilibrated with $8 \mathrm{~mol} / \mathrm{L}$ nitric acid.

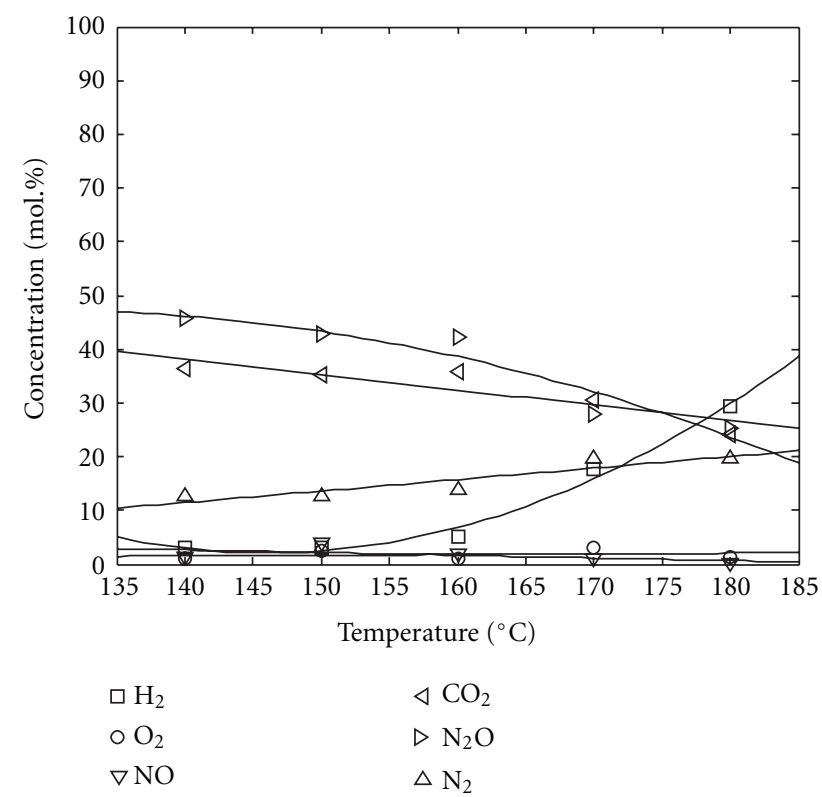

FIGURE 9: Effect of temperature on gaseous products in mole percentage during the single-phase decomposition of TBP equilibrated with $12 \mathrm{~mol} / \mathrm{L}$ nitric acid.

For a second order reaction in a plug flow reactor with an initial reactant ratio different than unity, the rate equation is derived from the above equation using power law model as follows:

$$
k \tau=\frac{1}{C_{\mathrm{TBP}_{0}}(M-1)} \ln \left(\frac{M-X_{\mathrm{TBP}}}{M\left(1-X_{\mathrm{TBP}}\right)}\right), \quad \text { where } M \neq 1
$$

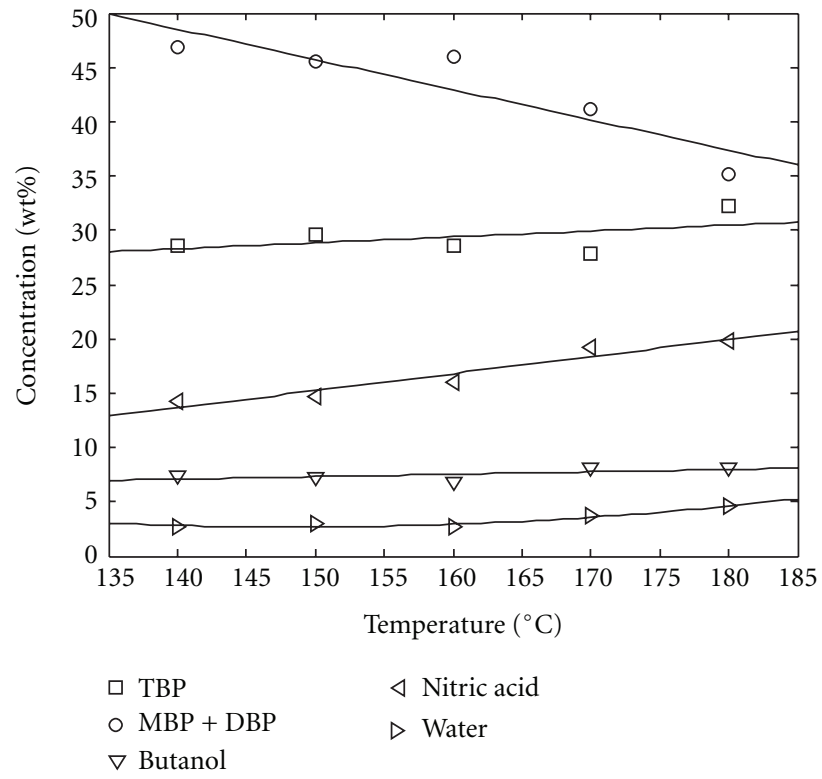

FIGURE 10: Effect of temperature on liquid product in weight percentage during the single-phase decomposition of TBP equilibrated with $12 \mathrm{~mol} / \mathrm{L}$ nitric acid.

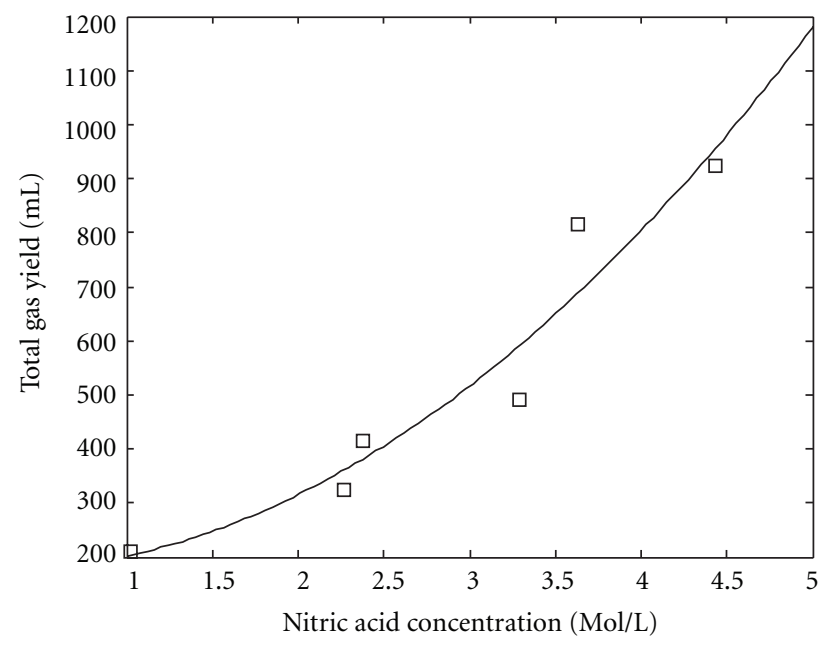

FIGURE 11: Effect of concentration of nitric acid on gas formation.

The value of rate constant $k$ was determined from (2). For different operating temperatures, the obtained $k$ values are listed in Table 5. Activation energy was calculated by using Arrhenius equation and it was found to be $-47.39 \pm$ $0.25 \mathrm{~kJ} \mathrm{~mol}^{-1}$.

3.5. A Possible Mechanism for Thermal Decomposition of Nitrated TBP. From the analysis of reaction products observed during the thermal decomposition of TBP in presence of nitric acid, the following mechanism is proposed.

Initially in the presence of acid, TBP is subjected to hydrolysis to produce DBP and butanol. DBP is further hydrolyzed to MBP and butanol [29]. MBP, however, remained 


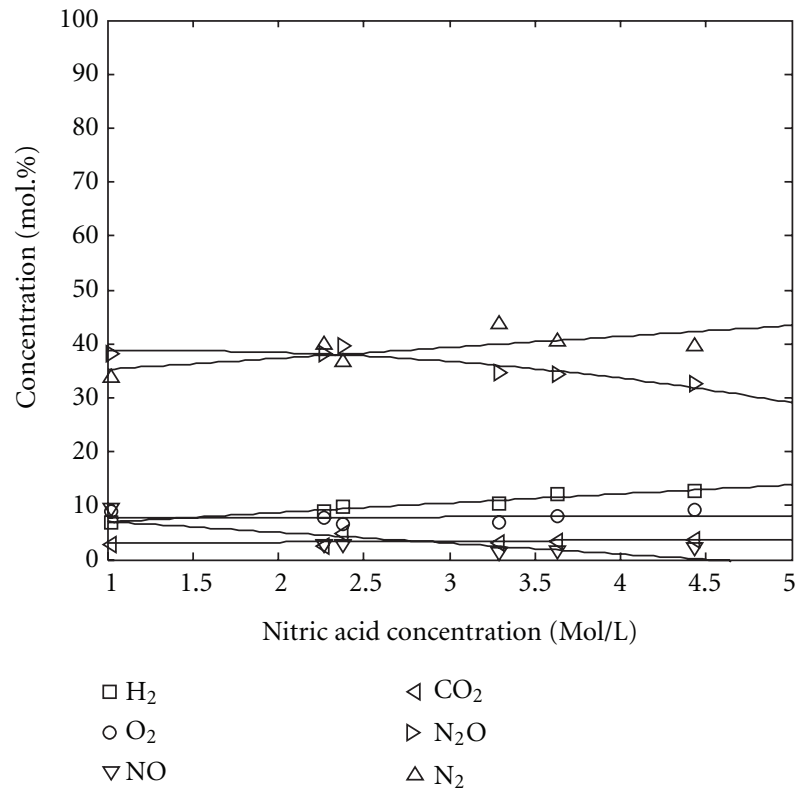

FIGURE 12: Effect of nitric acid concentration of TBP decomposition on gas formation in mole percentage.

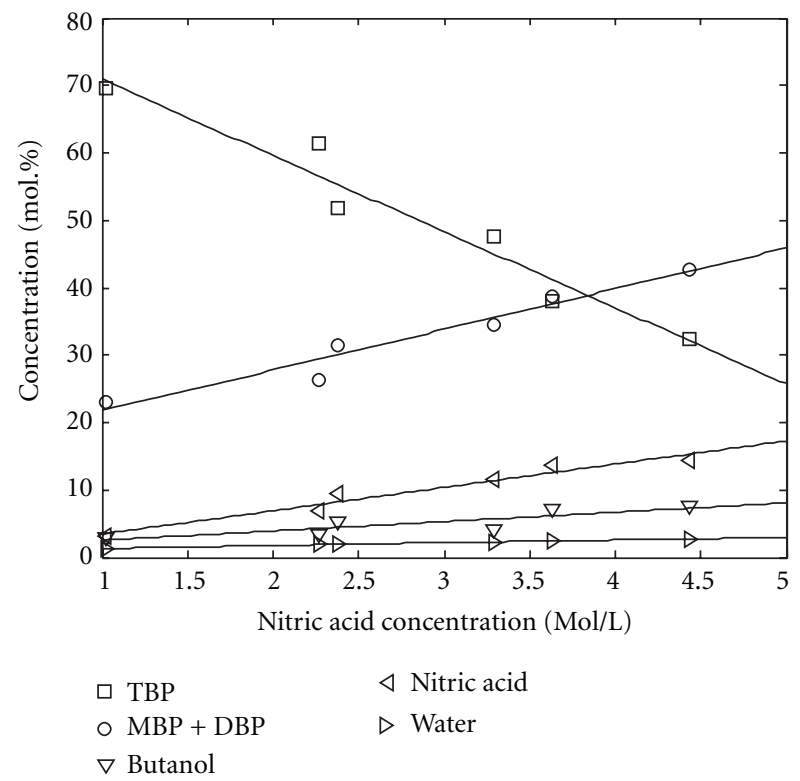

FIGURE 13: Effect of nitric acid concentration on TBP decomposition on liquid product formation.

in the reaction mixture and possibly undergoes decomposition as no phosphoric acid was detected as follows:

$$
\begin{aligned}
& \left(\mathrm{C}_{4} \mathrm{H}_{9} \mathrm{O}\right)_{3} \mathrm{PO}+\mathrm{H}_{2} \mathrm{O} \\
& \quad \longrightarrow\left(\mathrm{C}_{4} \mathrm{H}_{9} \mathrm{O}\right)_{2} \mathrm{POOH}+\mathrm{C}_{4} \mathrm{H}_{9} \mathrm{OH} \\
& \left(\mathrm{C}_{4} \mathrm{H}_{9} \mathrm{O}\right)_{2} \mathrm{POOH}+\mathrm{H}_{2} \mathrm{O} \\
& \quad \longrightarrow \mathrm{C}_{4} \mathrm{H}_{9} \mathrm{OPO}(\mathrm{OH})_{2}+\mathrm{C}_{4} \mathrm{H}_{9} \mathrm{OH}
\end{aligned}
$$

It was also suggested by Wilkinson and Williams [30] that TBP could directly react with nitric acid and form DBP via transesterification reaction. DBP formed is prone to nitration yielding MBP and butyl nitrate as

$$
\begin{aligned}
& \left(\mathrm{C}_{4} \mathrm{H}_{9} \mathrm{O}\right)_{2} \mathrm{POOH}+\mathrm{HNO}_{3} \\
& \quad \longrightarrow \mathrm{C}_{4} \mathrm{H}_{9} \mathrm{OPO}(\mathrm{OH})_{2}+\mathrm{C}_{4} \mathrm{H}_{9} \mathrm{ONO}_{2} \\
& \mathrm{C}_{4} \mathrm{H}_{9} \mathrm{OPO}(\mathrm{OH})_{2}+\mathrm{HNO}_{3} \\
& \quad \longrightarrow \mathrm{PO}(\mathrm{OH})_{3}+\mathrm{C}_{4} \mathrm{H}_{9} \mathrm{ONO}_{2}
\end{aligned}
$$

Barney and Copper [31] suggested that butanol, formed during the hydrolysis of TBP, undergoes an esterification reaction with nitric acid to yield butyl nitrate. The reaction might take place in vapor phase as prevailing temperatures $\left(>130^{\circ} \mathrm{C}\right)$ were greater than the boiling point of butanol $\left(117^{\circ} \mathrm{C}\right)$ and nitric acid $\left(84-121^{\circ} \mathrm{C}\right)$ as

$$
\mathrm{C}_{4} \mathrm{H}_{9} \mathrm{OH}+\mathrm{HONO}_{2} \longrightarrow \mathrm{C}_{4} \mathrm{H}_{9} \mathrm{ONO}_{2}+\mathrm{H}_{2} \mathrm{O}
$$

A simple way for thermal decomposition of nitric acid vapor has also been suggested in the literature $[32,33]$

$$
4 \mathrm{HNO}_{3} \longrightarrow 2 \mathrm{H}_{2} \mathrm{O}+4 \mathrm{NO}_{2}+\mathrm{O}_{2}
$$

Butyl nitrate, formed from (4) and (5), is highly unstable even at room temperature. Therefore, it may decompose to yield butylaldehyde, nitrous acid, and hydrogen gas as follows as

$$
\begin{gathered}
\mathrm{C}_{4} \mathrm{H}_{9} \mathrm{ONO}_{2} \longrightarrow \mathrm{C}_{4} \mathrm{H}_{9} \mathrm{O}^{\bullet}+\mathrm{NO}_{2} \\
\mathrm{C}_{4} \mathrm{H}_{9} \mathrm{O}^{\bullet} \longrightarrow \mathrm{CH}_{3} \mathrm{CH}_{2} \mathrm{CH} 2 \mathrm{CHO}+\mathrm{H}^{\bullet} \\
\mathrm{H}^{\bullet}+\mathrm{H}^{\bullet} \longrightarrow \mathrm{H}_{2} \\
\mathrm{H}^{\bullet}+\mathrm{NO}_{2} \cdot \longrightarrow \mathrm{HNO}_{2}
\end{gathered}
$$

As per Hiskey et al. [34], butylaldehyde is also highly reactive in acidic medium. It may react with nitrogen dioxide to yield carbon monoxide, nitric oxide, and water vapor as

$$
\mathrm{C}_{4} \mathrm{H}_{8} \mathrm{O}+7 \mathrm{NO}_{2} \cdot \longrightarrow 4 \mathrm{CO}+4 \mathrm{H}_{2} \mathrm{O}+7 \mathrm{NO}
$$

Carbon monoxide could be oxidized to carbon dioxide in the presence of oxygen as follows:

$$
2 \mathrm{CO}+\mathrm{O}_{2} \longrightarrow 2 \mathrm{CO}_{2}
$$

Bachman et al. [35] had proposed that nitrous acid also undergoes decomposition in the following three different ways:

$$
\begin{gathered}
2 \mathrm{HNO}_{2} \longrightarrow \mathrm{NO}_{2}+\mathrm{NO}+\mathrm{H}_{2} \mathrm{O} \\
3 \mathrm{HNO}_{2} \longrightarrow \mathrm{HNO}_{3}+2 \mathrm{NO}+\mathrm{H}_{2} \mathrm{O} \\
4 \mathrm{HNO}_{2} \longrightarrow 2 \mathrm{HNO}_{3}+\mathrm{N}_{2} \mathrm{O}+\mathrm{H}_{2} \mathrm{O}
\end{gathered}
$$

This study has shown possible mechanism of generation of large quantities of gaseous components in the thermal runaway "red oil" explosion. Thus, decomposition reactions of butyl nitrate and nitrous acid may be responsible for major yield of hydrogen gas generated during the thermal decomposition of nitrated TBP. The presence of hydrogen in large amount at higher temperature and higher nitric acid concentration is reported for the first time in this work. 


\section{Conclusions}

The idea about continuous plug flow reactor to study the violent reaction between TBP and nitric acid was successfully applied and red oil was synthesized without any runaway conditions. It can be synthesized by using 100\% TBP equilibrated with $2 \mathrm{~mol} / \mathrm{L}$ nitric acid at $150^{\circ} \mathrm{C}$. During the decomposition of TBP equilibrated with nitric acid in a flow reactor, pressurization of reactor system to dangerous level is prevented as the decomposition is conducted at atmospheric pressure, thus it can be concluded that sufficient venting is one of the most important factors to prevent pressurization of the reactor systems. Furthermore, at higher concentration of nitric acid and temperature, that is, higher than $8 \mathrm{~mol} / \mathrm{L}$ and $150^{\circ} \mathrm{C}$, respectively, the rate of generation of gaseous products increases linearly. Hence the concentration of nitric acid and temperature of reactor play an important role to prevent runaway reaction. It is always necessary to keep the temperature of the reactor below its runaway initiation temperature.

The thermal decomposition of TBP equilibrated with nitric acid over the temperature range $130-180^{\circ} \mathrm{C}$ is an irreversible, first order reaction with respect to TBP as well as nitric acid concentration. Activation energy of $47.39 \pm$ $0.25 \mathrm{~kJ} \mathrm{~mol}^{-1}$ was estimated from experimental runs. In both that is, concentration and temperature effect, the decomposition of TBP increases to produce MBP, DBP, and butanol which further undergo decomposition to produce a large amount of gases. At higher temperature and concentration of nitric acid, the generation of gases is quite high which may lead to runaway condition. Thus, it is concluded that adequate venting has to be provided to the evaporator/concentrator so that pressurization of the system does not occur and volume reduction of waste aqueous raffinate could be carried out safely.

The results obtained during decomposition of TBP equilibrated with nitric acid are useful for safety analysis of possible runaway reaction during evaporative concentration of radioactive acidic waste in nuclear fuel reprocessing facility.

\section{Nomenclature}

$C_{\mathrm{TBP}_{0}}$ : Initial concentration of TBP

$\mathrm{C}_{\mathrm{HNO}_{3}}$ : Initial concentration of $\mathrm{HNO}_{3}$

$M: \quad C_{\mathrm{HNO}_{3}} / C_{\mathrm{TBP}_{0}}$ initial ratio of the reactants

$X_{\text {TBP }}$ Conversion of TBP

$\tau: \quad$ Residence time, $\mathrm{s}$

$-r_{A}$ : Reaction rate

$K: \quad$ Rate constant.

\section{Acknowledgments}

This work was performed under a collaborative project between ICT Mumbai and IGCAR, Kalpakkam, India. Financial support from Government of India, DAE, Indira Gandhi Centre of Atomic Research, Kalpakkam, India, is sincerely acknowledged.

\section{References}

[1] A. Wright and P. Hartmann, "Review of physical and chemical properties of tributyl phosphate/diluent/nitric acid systems," Separation Science and Technology, vol. 45, no. 12, pp. 1753$1762,2010$.

[2] A. J. Moffat and R. D. Thompson, "The chemical stability of tributyl phosphate in some nitrate and chloride systems," Journal of Inorganic and Nuclear Chemistry, vol. 16, no. 3-4, pp. 365-366, 1961.

[3] R. M. Wagner, "Investigation of explosive characteristic of purex solvent decomposition product (red oil)," Tech. Rep. U.S. AEC Report HW-27492.

[4] W. W. Schulz and J. D. Navratil, Eds., Science and Technology of Tributyl Phosphate, Synthesis, Properties, Reactions and Analysis, CRC Press, Boca Raton, Fla, USA, 1984.

[5] P. L. Gordon, C. O’Dell, and J. G. Watkin, "Synthesis and energetic content of red oil," Journal of Hazardous Materials, vol. 39, no. 1, pp. 87-105, 1994.

[6] P. L. Gordon, C. O’Dell, and J. G. Watkin, "Investigation of red oil decomposition by simulated Hanford tank wastes," Journal of Hazardous Materials, vol. 39, no. 1, pp. 69-86, 1994.

[7] M. L. Hyder, "Safe condition of contacting nitric acid or nitrate with tributyl phosphate," Tech. Rep. WSRC-TR-94-059, 1994.

[8] T. S. Rudisill and W. J. Crooks, "Initiation temperature for runaway tri- $n$-butyl phosphate/nitric acid reaction," Separation Science and Technology, vol. 38, no. 12-13, pp. 2725-2739, 2003.

[9] V. N. Usachev and G. S. Markov, "Incidents caused by red oil phenomena at semi-scale and industrial radiochemical units," Radiochemistry, vol. 45, no. 1, pp. 1-8, 2003.

[10] C. F. Jenkins, "Performance of evaporator in high level radioactive chemical waste service," Tech. Rep. WSRC- TR-9700297.

[11] Y. Shuyao, S. Yu, and T. Tianzhen, "Investigation of the influence of various factors on the formation of strong complexants in purex systems," Radiation Physics and Chemistry, vol. 33, no. 6, pp. 599-602, 1989.

[12] A. Tahraoui and J. H. Morris, "Decomposition of solvent extraction media during nuclear reprocessing: literature review," Separation Science and Technology, vol. 30, no. 13, pp. 2603-2630, 1995.

[13] "Summary of red oil issues at hanford," DOE Report WHCSD-WM-TI-466.

[14] R. N. Robinson, D. M. Gutowski, and W. Yeniscavich, Control of Red Oil Explosions in Defense Nuclear Facilities, Defense Nuclear Facilities Safety Board Technical Report, 2003.

[15] D. D. Dicholkar, L. K. Patil, V. G. Gaikar, S. Kumar, U. K. Mudali, and R. Natarajan, "Direct determination of tri- $n$ butyl phosphate by HPLC and GC methods," Journal of Radioanalytical and Nuclear Chemistry, vol. 291, no. 3, pp. 739-743, 2012.

[16] B. Marlet and C. Pommier, "Gas chromatographic analysis of the extraction solvent used in nuclear fuel reprocessing plants," Journal of Chromatography, vol. 325, no. 1, pp. 75-85, 1985.

[17] M. A. Ali and A. M. Al-Ani, "Gas chromatographic determination of tributyl phosphate, dibutyl phosphate and butyl phosphate in kerosene solutions," Analyst, vol. 116, no. 10, pp. 1067-1069, 1991.

[18] Y. Kuno, T. Hina, T. Akiyama, and M. Matsui, "Simultaneous determination of tributyl phosphate and dibutyl phosphate 
in spent fuel reprocessing streams by gas chromatography," Journal of Chromatography, vol. 537, no. 1-2, pp. 489-493, 1991.

[19] M. H. Campbell, "Gas chromatographic analysis of solvent used in reactor fuel reprocessing and fission product recovery," Analytical Chemistry, vol. 38, no. 2, pp. 237-240, 1966.

[20] M. V. Krishnamurthy and R. Sampathkumar, "Radiationinduced decomposition of the tributyl phosphate-nitric acid system: role of nitric acid," Journal of Radioanalytical and Nuclear Chemistry, vol. 166, no. 5, pp. 421-429, 1992.

[21] S. Mandal and D. Kundu, "Rapid determination of phosphate by indirect complexometric method," Journal of the Indian Chemical Society, vol. 82, no. 11, pp. 1030-1031, 2005.

[22] K. E. Grant, G. M. Mong, S. A. Clauss, K. L. Wahl, and J. A. Campbell, "Determination of monobutyl phosphate and dibutyl phosphate in mixed hazardous wastes by ionpair chromatography," Journal of Radioanalytical and Nuclear Chemistry, vol. 220, no. 1, pp. 31-35, 1997.

[23] A. Dodi and G. Verda, "Improved determination of tributyl phosphate degradation products (mono- and dibutyl phosphates) by ion chromatography," Journal of Chromatography A, vol. 920, no. 1-2, pp. 275-281, 2001.

[24] V. Ruiz-Calero and M. T. Galceran, "Ion chromatographic separations of phosphorus species: a review," Talanta, vol. 66, no. 2, pp. 376-410, 2005.

[25] K. E. Williams, S. J. Haswell, D. A. Barclay, and G. Preston, "Determination of total phosphate in waste waters by on-line microwave digestion incorporating colorimetric detection," Analyst, vol. 118, no. 3, pp. 245-248, 1993.

[26] N. Krishnamurthy and A. V. Suryanarayana, Journal of Analytical Chemistry, vol. 312, p. 548, 1982.

[27] G. D. Christian and F. J. Feldman, "Determination of nonmetals by atomic absorption spectrophotometry," Analytica Chimica Acta, vol. 40, pp. 173-179, 1968.

[28] P. Bocek, V. Dolnik, M. Deml, and J. Janak, "Separation and determination of the degradation products of tributyl phosphate by high-speed analytical isota chophoresis," Journal of Chromatography A, vol. 195, no. 2, pp. 303-305, 1980.

[29] R. M. Wagner, "The hydrolysis product of tributyl phosphate and their effect on the tributyl phosphate process for uranium recovery," Tech. Rep. U.S.AEC Report HW-19959.

[30] R. W. Wilkinson and T. F. Williams, "The radiolysis of tri- $n$ alkyl phosphates," Journal of the Chemical Society, pp. 40984107, 1961.

[31] G. S. Barney and T. D. Cooper, "The chemistry of tributyl phosphate at elevated temperatures in the plutonium finishing plant process vessels," Tech. Rep. WC-EP-0737.

[32] Y. S. Duh, C. Lee, C. C. Hsu, D. R. Hwang, and C. S. Kao, "Chemical incompatibility of nitrocompounds," Journal of Hazardous Materials, vol. 53, no. 1-3, pp. 183-194, 1997.

[33] H. S. Johnston, L. Foering, Y. S. Tao, and G. H. Messerly, "The kinetics of the thermal decomposition of nitric acid vapor," Journal of the American Chemical Society, vol. 73, no. 5, pp. 2319-2321, 1951.

[34] M. A. Hiskey, K. R. Brower, and J. C. Oxley, "Thermal decomposition of nitrate esters," Journal of Physical Chemistry, vol. 95, no. 10, pp. 3955-3960, 1991.

[35] G. B. Bachman, L. M. Addison, J. V. Hewett, L. Kohn, and A. Millikan, "Nitration studies. I. General mechanism of vapor phase nitration," Journal of Organic Chemistry, vol. 17, no. 7, pp. 906-913, 1952. 

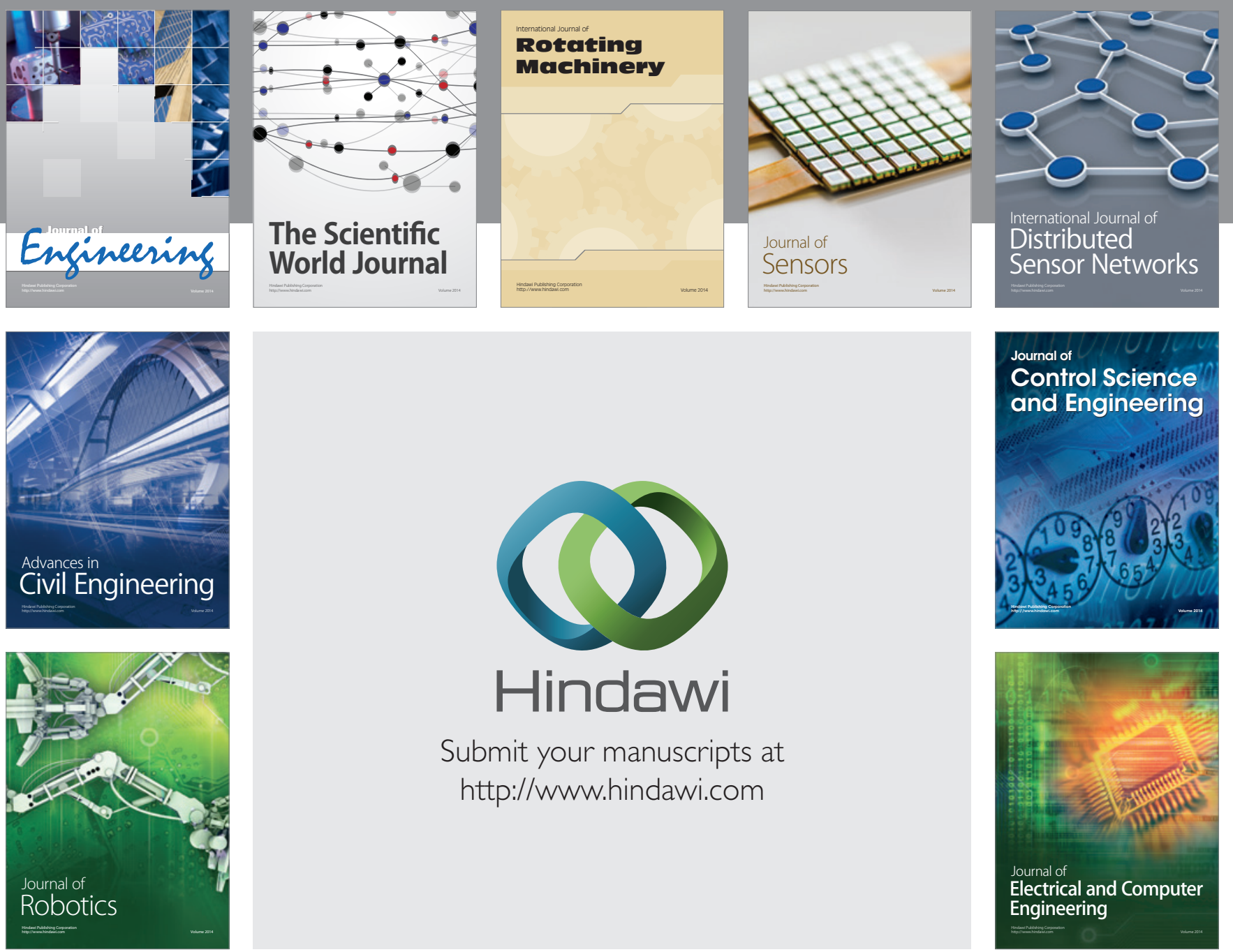

Submit your manuscripts at

http://www.hindawi.com
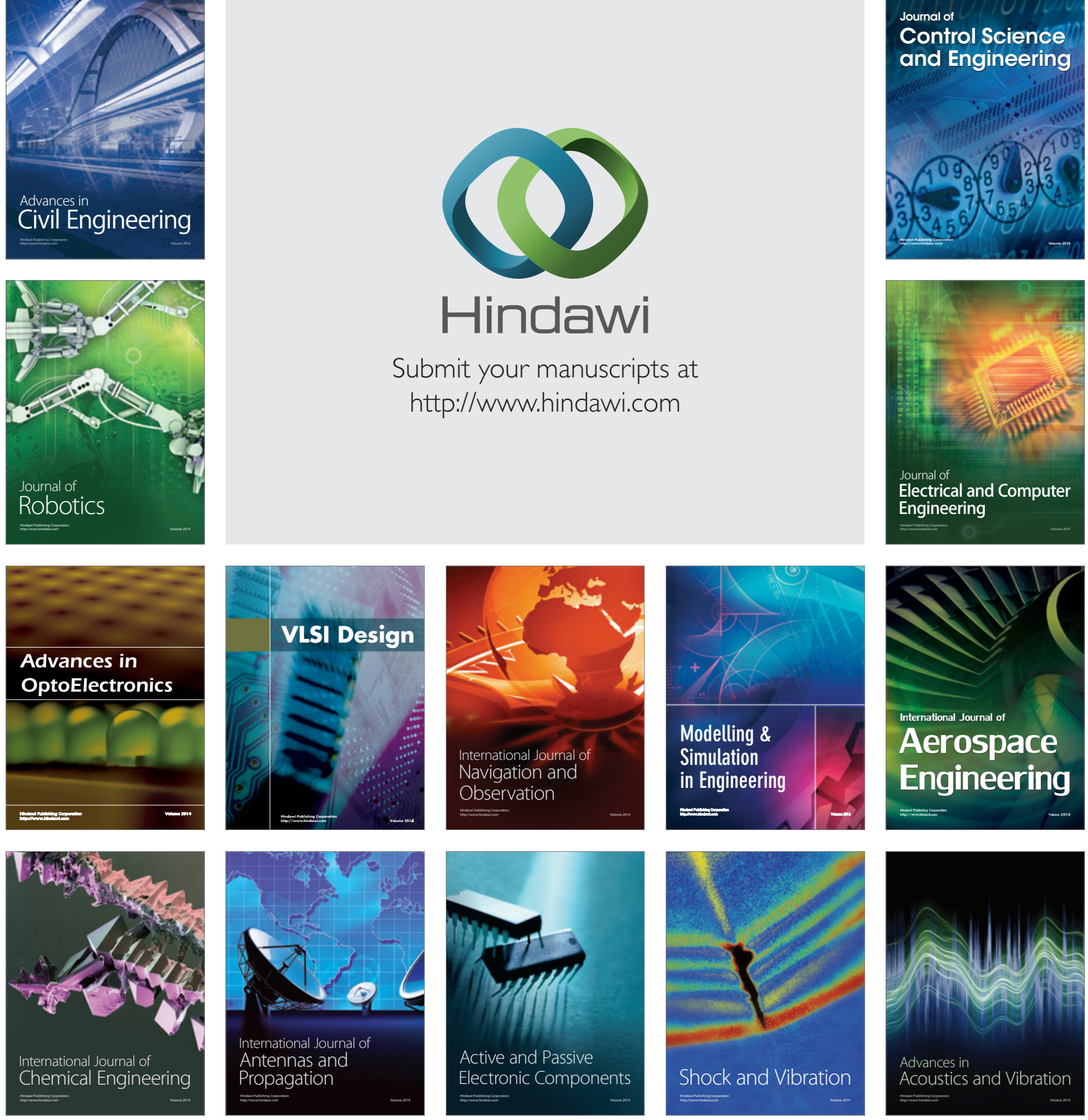